\title{
Fresh and Mechanical Characteristics of Eco-efficient GPC Incorporating Nano-silica: An Overview
}

\author{
Hiwa Hamid Sharif \\ Civil Engineering Department \\ College of Engineering \\ University of Halabja \\ Halabja, Iraq \\ Hiwa.sharif@uoh.edu.iq \\ Rabar H. Faraj \\ Civil Engineering Department \\ College of Engineering \\ University of Halabja \\ Halabja, Kurdistan Region, Iraq \\ Rabar.faraj@uoh.edu.iq
}

\author{
Hemn Unis Ahmed \\ Civil Engineering Department \\ College of Engineering \\ University of Sulaimani \\ Sulaimaniyah, Iraq \\ hemn.ahmed@univsul.edu.iq
}

\author{
Arass Omer Mawlod \\ Civil Engineering Department \\ College of Engineering \\ University of Raparin \\ Sulaimaniyah, Iraq \\ Arass.omar@uor.edu.krd
}

\section{Article Info \\ Volume 6 - Issue 2- December 2021 \\ DOI: \\ 10.24017/science.2021.2.6}

\section{Article history:}

Received 2/9/2021

Accepted 21/11/2021

\section{Keywords:}

geopolymer concrete;

Nano silica; workability;

Flexural Strength; Splitting

Tensile Strength;

Compressive Strength

\begin{abstract}
Geopolymer concrete is an inorganic concrete that uses industrial or agro byproduct ashes as the main binder instead of ordinary Portland cement; this leads to the geopolymer concrete being an eco-efficient and environmentally friendly construction material. Nanotechnology is one of the most active research areas with novel science and useful applications that have gradually gained attention, especially during the last two decades. Recently efforts have been made to incorporate nanoparticles in construction materials to enhance properties and produce concrete with improved performances. Progress in improving geopolymer concrete (GPC) is fast becoming a viable substitute for traditional cement-based concrete. That is because GPC is considered an eco-efficient and green concrete that consumes many waste materials. To improve the performance of GPC, several methods have been investigated, including the using of nanomaterials to enhance its chemical reactivity and provide fine particles to fill its nanopores and voids. In this paper, an overview was carried out to show the impact of nanosilica (nS) inclusions on the fresh and mechanical characteristics of GPC. Based on the analyzed data, incorporating $n S$ affects the fresh properties adversely while improving the mechanical performance up to an appropriate dosage of the $n S$.
\end{abstract}

Copyright $\left({ }^{\circ} 2021\right.$ Kurdistan Journal of Applied Research. All rights reserved. 


\section{INTRODUCTION}

Concrete is the most widely used construction material in the world [1], usually portland cement is used to bind the ingredients of the concrete composites. However, the production of portland cement is partly responsible for the greenhouse effect and significantly contributes to global warming [2]. The manufacturing process of cement emits nearly 1 ton of carbon dioxide $\left(\mathrm{CO}_{2}\right)$ for every ton of cement, which occupies around $7 \%$ of the total global green gas emissions [3]. Therefore, to decrease the environmental impact of Portland cement, a lot of research has been done to develop new materials to be an alternative to Portland cement [4]. Among them, geopolymer technology was developed first by Davidovits in France, 1970 [5]. It is supposed that geopolymer composites are the third group of primary construction materials in human written history after lime and cement [6].

The drawback of GPC concerning global warming is around 70\% lower than Portland cement concrete; this is because of the high consumption of industrial and agro byproduct materials inside the GPC mixtures, such as ground granulated blast furnace slag (GGBFS), rice husk ash (RHA), fly ash (FA), and palm oil fuel ash (POFA) [7].

The composition of the geopolymer concrete composite is consists of source binder materials, aggregates, and high alkalinity liquids. Source binder materials like ground granulated blast furnace slag (GGBFS), fly ash (FA), palm oil fuel ash (POFA), and rice husk ash (RHA) [8]. Aggregates are coarse and fine aggregate made from river naturally or crushed stone with required properties and gradations [9]. Alkali activators are mixtures of potassium silicate and potassium hydroxide, or sodium silicate and sodium hydroxide [9]. The polymerization of these materials produces solid concrete that is nearly identical to normal concrete [10].

The polymerization mechanism could be briefly explained as follows; in the first stage, dissolution of the silicate and aluminum elements of the binder inside the high alkalinity aqueous solution produces ions of silicon and aluminum oxide. In the second stage, a mixture of silicate, aluminate, and aluminosilicate species, which through a contemporaneous operation of poly-condensation-gelation further condensation, finally produces an amorphous gel [11]. The performance of geopolymer composites can be influenced by various factors, including the type and content of source binder materials, sodium silicate to sodium hydroxide ratio, the molarity of $\mathrm{NaOH}$, excess water, mix proportions, and the technique of curing [9, 12].

In the last two decades, scientists and researchers studied nanotechnology and nanoscience in the various sectors of life, mainly due to the progress of convenient techniques of characteristics and reactions control in the nanoscale [13]. Therefore, nanoparticles (NPs) were introduced with conventional concrete and geopolymer matrices to enhance durability issues, mechanical properties, and physical structure of the geopolymer mixture [14, 15].

The effect of adding nS to geopolymer composites on their fresh and mechanical properties was examined in this paper. As a result, the impact of $\mathrm{nS}$ content on the mechanical properties and workability of the geopolymer composite were discussed in the most recent and previously published publications.

\section{Nanomaterials in GPC}

Nanotechnology enables researchers to monitor and reorganize the material at the atomic and molecular scale of 1 to $100 \mathrm{~nm}$ and define new properties at the level of atoms and molecules $[15,16]$. The mechanical characteristics, chemical reactivity, surface energy, morphology, the conductivity of electrons, and optical absorption of composites were considerable changes in switching off one material from macro size to the nanoparticle scale [17].

In the civil engineering field, nanomaterials stand out as new materials, and nanotechnology has been used in many applications and products. The utilization of nanomaterials in traditional cement-based concrete has been broadly studied in the literature $[15,13]$. In the same context, several investigations have been carried out to study the influences of nanomaterial's inclusion on the mechanical performance and chemical durability of GPC composites [18,19], structural performance [20], fresh and microstructural properties [21], 
physio-mechanical properties [22], permeability [23] and fire resistance [24]. Moreover, in the literature, a variety of nano-materials like nS [18-27], nano-alumina [28], nano-titanium oxide [29], nano-clay [30], nano-metakaolin [31] and carbon nanotubes [32] were used in GPC. Among them, the most widely used nanomaterial is the $\mathrm{nS}$ due to its chemical composition that has the nano-filing effect and pozzolanic reactivity $[33,34]$. Nano-silica has mostly been employed in Portland cement-based concrete to boost internal structure, durability, and mechanical properties because of its ability to increase cement hydration and pozzolanic activity through nucleation. Another reason to substitute cement with nano-silica-rich materials in concrete was to minimize the impact of the $\mathrm{CO}_{2}$ footprint of concrete on the air $[3]$.

Because of the filling effect of pores and voids among cement particles by nanomaterials, free water's motionlessness occurs when the nanomaterials are introduced to the cement granulations, known as the filler effect. Furthermore, through the pozzolanic reaction, nanomaterials participate in the assembly of new calcium silicate hydrate $(\mathrm{C}-\mathrm{S}-\mathrm{H})$ gels and consequently enhance the bond strength characteristics of the mix by improving the interfacial transition zone between the binder pastes and aggregates [35]. When the curing condition of the GPC is ambient curing resulting poor compressive strength and gets strength slowly [36]. However, it has an excellent compressive strength in heat-cured conditions, which restricts the application of GPC to precast structural members [37]. So, one of the methods tried to tackle this problem is using nanomaterials to accelerate the chemical reactions inside the GPC to obtain sufficient strength in the ambient curing [20,38].

\section{Fresh Properties of GPC}

The term workability in the science of concrete technology refers to the behavior of concrete in the fresh state, and it is defined as the useful internal work required to generate full compaction of the concrete [46]. It is familiar that the mechanical, physical, internal structure, and durability of concrete are strongly affected by the fresh concrete's characteristics. Water to cement ratio, aggregate form, size, gradation, surface texture, presence of mineral and chemical admixtures, climate condition, and cement content all affect the concrete workability [39]. To evaluate the workability, slump cone [41], slump flow [42], Vebe [43], compacting factor [44], and flow table [45] tests are widely utilized. As shown in Fig.1 and Fig.2, several investigations have been performed to demonstrate the impact of $\mathrm{nS}$ content on the fresh characteristics of GPC mixtures.

A study has been conducted by Mustakim et al. [21] to determine the impact of nS content on the fresh, internal structure and mechanical characteristics of slag/fly ash-based GPC. They used different dosages of $\mathrm{nS}$ range from 0 to $2.5 \%$. Their results revealed that the GPC's workability was increased by $27 \%, 26 \%, 31 \%, 30 \%$, and $27 \%$, at $0.5 \%, 1 \%, 1.5 \%, 2 \%$, and $2.5 \% \mathrm{nS}$ content, respectively, that may be due to sliding the concrete particle on each other as the particles of $\mathrm{nS}$ are the sphere in shape [21]. Another study displayed the influence of $\mathrm{nS}$ inclusions on the workability of fly ash-based GPC. According to their results, the inclusion of $6 \%$ of $\mathrm{nS}$ caused an improvement in the slump value by $8 \%$ compared to the control geopolymer concrete mixture [20]. In addition, a study has been carried out to show the effect of $\mathrm{nS}$ addition on the strength of natural pozzolana-based GPC. They observed that the workability was risen with the increment of $\mathrm{nS}$ content up to $2.5 \%$, and beyond that slump reduction was observed. The increase in the workability may be argued to the colloidal nature of $\mathrm{nS}$, while, fall in the slump at higher $\mathrm{nS}$ dosage could be related to an increase in the water demand of nanoparticles that have a greater specific surface area due to the nature of their nanoscales [25]. Simultaneously, the permeability of slag-based GPC was examined under the influence of micro and nano-silica. Results indicated that addition of $0.5,1,3$ and $5 \% \mathrm{nS}$ lowered the slump value by $9 \%, 27 \%, 50 \%$ and $82 \%$, respectively. This reduction in a slump can be attributed to the fact that $\mathrm{nS}$ particles are smaller than the binder of the GPC particles; therefore, a high amount of water is required due to the high surface area. Consequently, the workability of the GPC mixtures decreased [23]. 
In addition, studies have been carried out to show how the presence of $\mathrm{nS}$ affects the fire resistance and mechanical qualities of recycled aggregate fly ash-based GPC. They discovered that adding $\mathrm{nS}$ to the GPC mixture significantly reduces its workability, especially at high dosage replacement. The maximum reduction in the slump flow of the GPC was $16 \%$ at $3 \%$ of $\mathrm{nS}$ content compared to the benchmark GPC mixture without any nS content [24]. Another investigation on the effects of $\mathrm{nS}$ and regular Portland cement content on the characteristics of fly ash-based GPC was undertaken in the same context. The mean slump flows value of $0 \%$, $1 \%, 2 \%$ and $3 \% \mathrm{nS}$ content were $697,621,645$ and $568 \mathrm{~mm}$, respectively. The decrease in the slump flow value was more noticeable at large $\mathrm{nS}$ dosages. This outcome was argued to be the high surface area of $\mathrm{nS}$ that contained many unsaturated bonds of Si-O (silicon-oxygen), which absorbed some part of water content from alkali liquid solutions leading to the formation of Si-OH and as a consequence, a stiffer GPC mixture was produced [26].

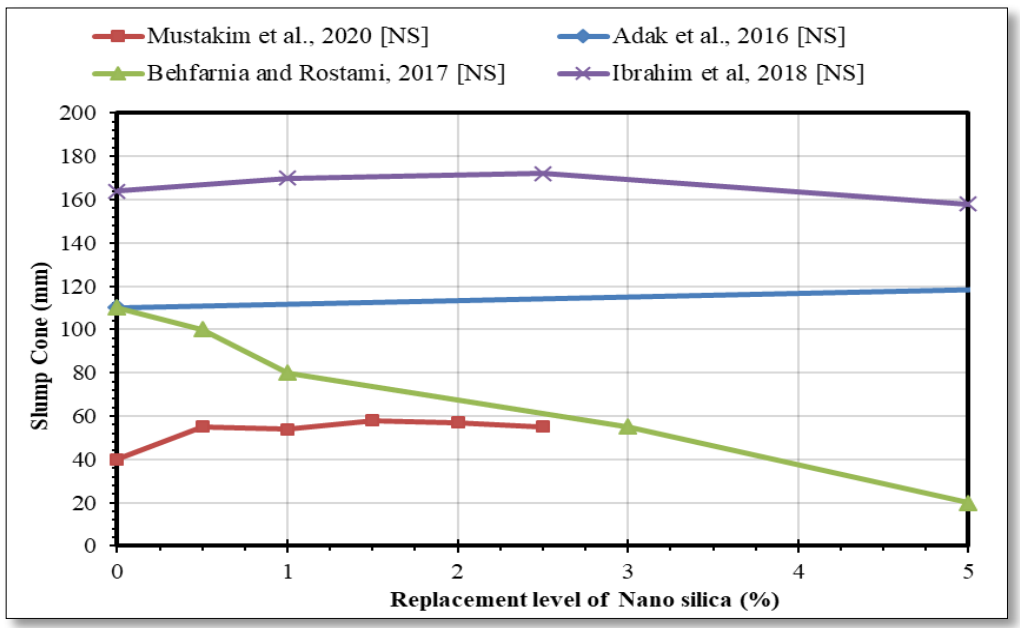

Figure 1: Variation of the slump cone of GPC incorporating nS

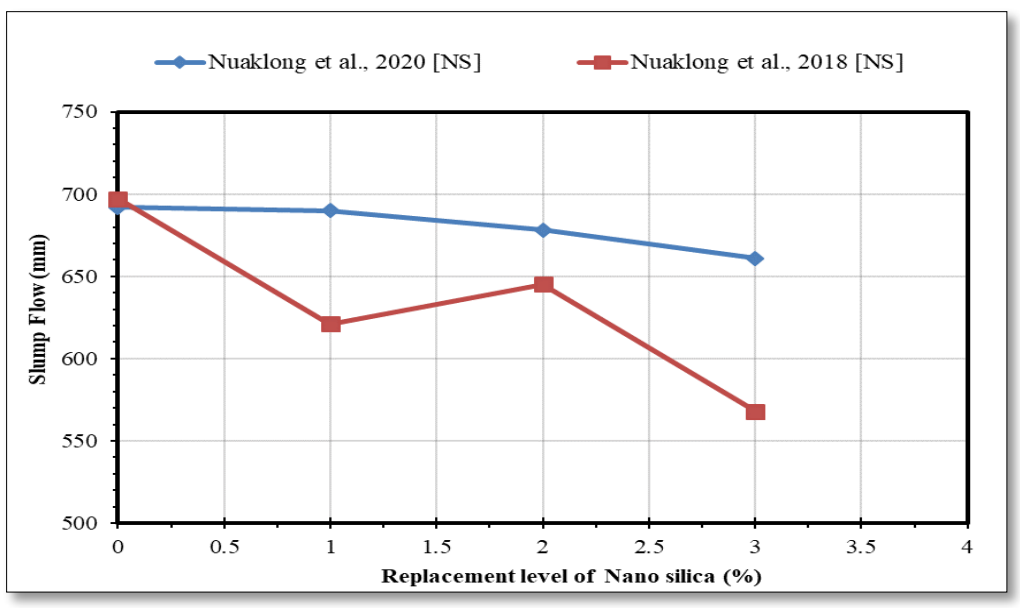

Figure 2: Variation of the slump flow of GPC incorporating nS 


\section{Mechanical Properties of GPC}

\subsection{Compressive Strength}

One of the most important mechanical properties of concrete structures is the compressive strength, and it usually gives a general performance about the quality of the concrete [46]. Compressive strength tests are conducted by following the standard test methods of ASTM C39 [47], or BS EN 12390-3 [48] to determine the compressive strength of the concrete specimens. Table 1 shows the impact of incorporating $\mathrm{nS}$ on GPC compressive strength after three, seven, and twenty-eight days of curing. Overall, the data suggest that adding nS to GPC improves compressive strength up to a certain quantity of $\mathrm{nS}$ dosages.

An investigation has been carried out by Mustakim et al. [21] on the fresh, internal structural, and also mechanical characteristics of FA/GGBFS-based GPC with $\mathrm{nS}$ at various volume fractions. They discovered that all nano-silica-containing combinations had higher compressive strength than virgin mixtures without nS. After curing at 28 days' room temperature, the highest compressive strength was reported at a dosage of $1.5 \% \mathrm{nS}$, which increased compressive strength by $11 \%$ above the normal mix. The increase in strength can be attributed to the filling of nanopores inside the GPC by silica nanoparticles that make the matrix denser and more compact. In addition, due to chemical characteristics of the $\mathrm{nS}$, which is rich in silica, accelerate the geopolymer reactions and make the geopolymer binder stronger, which eventually enhances the specimens' strength. Moreover, they prefer $1.5 \%$ of $\mathrm{nS}$ would be the optimum content for compressive strength improvement, beyond that dosage, it slightly reduced in the compressive strength according to overflowing availability in the matrix of unreacted $\mathrm{nS}$ particles, and the excess number of $\mathrm{nS}$ causes agglomerations between the $\mathrm{nS}$ particles that may have prevented silica dissolution, as a result of which voids form and, as a result, a reduction in the GPC's compressive strength [21]. The same findings have been made by $[19,24,27]$, who discovered that adding nS to GPC increases its compressive strength up to a specific dosage of $\mathrm{nS}$. Furthermore, based on the experimental finding of Nuaklong et al. [26], the incorporation of $\mathrm{nS}$ improves the compressive strength of the GPC up to $2 \%$ of $\mathrm{nS}$, and over that dosage decrease in the compressive strength was reported.

Similar to that, Khater [22] examined the impact of various dosages of $\mathrm{nS}$ on physiomechanical characteristics of GPC. Dosages from 0 to $8 \%$ were used. It was reported that the optimum dosage was $3 \%$ in terms of compressive strength, which was $36 \mathrm{MPa}$, while the correspondence compressive strength was $25 \mathrm{MPa}$. This optimum dosage (3\%) of $\mathrm{nS}$ was also reported by Behfarnia and Rostami [23] and Mahboubi et al. [30] in their studies. They investigated the permeability and durability properties of GPC with the inclusion of different $\mathrm{nS}$ contents. However, Rabiaa et al. [31] observed that $4 \%$ of $\mathrm{nS}$ was optimum content among 0 to $8 \%$ of $\mathrm{nS}$ dosages. According to Behfarnia and Rostami [23], adding 3\% of $\mathrm{nS}$ enhanced the 28-day compressive strength by $12 \%$. Meanwhile, there was a decline in compressive strength beyond this dosage. This result may support the fact that $\mathrm{nS}$ takes part in the pozzolanic reaction to make more calcium silicate hydrate $(\mathrm{C}-\mathrm{S}-\mathrm{H}) \mathrm{gel}$ and fill the pores inside the matrix in the range of nano-level. At the same time, the reduction in strength was related to agglomerations of $\mathrm{nS}$ particles in the geopolymer concrete mixture, followed by the formation of voids in the concrete matrix [23].

Another study was conducted on the impact of $\mathrm{nS}$ on the microstructure and strength of natural pozzolan-based GPC; they used $0,1,2.5,5$, and $7.5 \%$ of $\mathrm{nS}$. They discovered that adding $\mathrm{nS}$ to GPC enhanced its compressive strength, and the highest value (about 18\%) being for the specimens with $5 \%$ of $\mathrm{nS}$ dosage, whereas the minimum values were measured in the reference GPC mixture without the presence of $\mathrm{nS}$ [25]. Similarly, the addition of $\mathrm{nS}$ particles improves the structural performance of the GPC [20]. 
Table 1: Variation of the compressive strength of GPC incorporating different dosages of nS

\begin{tabular}{|c|c|c|c|c|c|c|c|c|c|}
\hline \multirow[t]{3}{*}{ Authors } & \multirow[t]{3}{*}{$\mathrm{nS} \%$} & \multicolumn{3}{|c|}{$\begin{array}{c}\text { Compressive Strength } \\
\text { (MPa) }\end{array}$} & \multirow[t]{3}{*}{ Authors } & \multirow[t]{3}{*}{$\mathrm{nS} \%$} & \multicolumn{3}{|c|}{$\begin{array}{c}\text { Compressive Strength } \\
\text { (MPa) }\end{array}$} \\
\hline & & 3 & 7 Day & 28 Day & & & 3 Day & 7 Day & 28 \\
\hline & & Day & & & & & & & Day \\
\hline \multirow{6}{*}{$\begin{array}{l}\text { Mustaki } \\
\text { m et al., } \\
2020[21]\end{array}$} & 0 & 8.95 & 32.9 & 56 & \multirow{6}{*}{$\begin{array}{c}\text { Khater H } \\
\text { M, } 2016 \\
{[22]}\end{array}$} & 0 & & 20.2 & 25.1 \\
\hline & 0.5 & 10.9 & 28.8 & 60.3 & & 1 & & 21.9 & 25.7 \\
\hline & 1 & 9.7 & 28.7 & 57.2 & & 3 & & 28.4 & 36 \\
\hline & 1.5 & 12.6 & 33.9 & 62.8 & & 5 & & 26.9 & 30 \\
\hline & 2 & 13.8 & 34.8 & 58.9 & & 7 & & 19.3 & 25.1 \\
\hline & 2.5 & 12.4 & 33.9 & 55.4 & & 8 & & 18.2 & 24 \\
\hline \multirow{2}{*}{$\begin{array}{l}\text { Çevik et } \\
\text { al., } 2018\end{array}$} & 0 & & & 51.63 & \multirow{2}{*}{$\begin{array}{l}\text { Emad et } \\
\text { al., } 2018\end{array}$} & 0 & & 43.2 & 62 \\
\hline & 3 & & & 48.4 & & 2 & & 51.9 & 77.7 \\
\hline
\end{tabular}

[18]

[27]

\begin{tabular}{cccc}
\hline Mahboub & 0 & 18.9 & 30.9 \\
\cline { 2 - 4 } i et al., & 1 & 22.8 & 37.8 \\
\cline { 2 - 4 } 2019 [30] & 2 & 24.6 & 44.5 \\
\cline { 2 - 4 } & 3 & 25.6 & 45.9
\end{tabular}

\begin{tabular}{cccc} 
Naskara & 0 & 21.6 & 24.6 \\
\cline { 2 - 4 } and & 0.2 & 17.1 & 19.24 \\
\cline { 2 - 4 } Chakrabor & 0.75 & 14.9 & 14.5 \\
\cline { 2 - 4 } ty, 2016 & 3 & 20.3 & 18.2
\end{tabular}

[55]

\begin{tabular}{|c|c|c|c|c|}
\hline \multirow{5}{*}{$\begin{array}{c}\text { Rabiaa et } \\
\text { al., } 2020 \\
{[31]}\end{array}$} & \multicolumn{2}{|l|}{0} & 29 & 38 \\
\hline & \multicolumn{2}{|l|}{2} & 31 & 42 \\
\hline & \multicolumn{2}{|l|}{4} & 36 & 48 \\
\hline & \multicolumn{2}{|l|}{6} & 34 & 45 \\
\hline & \multicolumn{2}{|l|}{8} & 32 & 43 \\
\hline \multirow{4}{*}{$\begin{array}{l}\text { Nuaklong } \\
\text { et al., } \\
2020 \text { [24] }\end{array}$} & \multicolumn{2}{|l|}{0} & 18.9 & 37.4 \\
\hline & \multicolumn{2}{|l|}{1} & 21.4 & 38.2 \\
\hline & \multicolumn{2}{|l|}{2} & 19.1 & 36.5 \\
\hline & \multicolumn{2}{|l|}{3} & 18.6 & 34.2 \\
\hline \multirow{4}{*}{$\begin{array}{l}\text { Nuaklong } \\
\text { et al., } \\
2018 \text { [26] }\end{array}$} & \multicolumn{3}{|l|}{0} & 32.9 \\
\hline & \multicolumn{3}{|l|}{1} & 39.6 \\
\hline & \multicolumn{3}{|l|}{2} & 42.6 \\
\hline & \multicolumn{3}{|l|}{3} & 31.6 \\
\hline Adak et & 0 & 23.3 & 29.7 & 35.11 \\
\hline al., 2016 & 6 & 21.7 & 35.8 & 46.43 \\
\hline
\end{tabular}

\begin{tabular}{|c|c|c|c|c|}
\hline Behfarnia & 0 & & & 56.3 \\
\hline and & 0.5 & & & 57.5 \\
\hline Rostami, & 1 & & & 60 \\
\hline 2017 [23] & 3 & & & 63 \\
\hline & 5 & & & 52 \\
\hline Patel et al., & 0 & & & 39 \\
\hline 2015 [19] & 0.5 & & & 40 \\
\hline & 1 & & & 41.2 \\
\hline & 1.5 & & & 42.4 \\
\hline Ibrahim et & 0 & 33 & 37.3 & 34.8 \\
\hline al, 2018 & 1 & 28.5 & 38.2 & 34.2 \\
\hline [25] & 2.5 & 28 & 39.4 & 37.4 \\
\hline & 5 & 27.3 & 44.4 & 42.1 \\
\hline & 7.5 & 20.7 & 37.8 & 40.9 \\
\hline
\end{tabular}

[20]

\subsection{Splitting Tensile Strength (STS)}

Concrete's splitting tensile strength is another significant mechanical property, and it can be measured indirectly by applying the standards test method of ASTM C496 [49] or BS EN 
12390-6 [50]. $150 * 300 \mathrm{~mm}$ or $100 * 200 \mathrm{~mm}$ cylinder specimens are used to evaluate the splitting tensile strength to which loads are applied to axial lines opposite to each other. A constant compression stress loads range from 0.7 to $0.3 \mathrm{MPa}$ is applied [46]. The load is increased until failure along the vertical diameter takes place $[40,51]$. Table 2 demonstrates some literature studies that have been conducted to illustrate the effects of adding $\mathrm{nS}$ on the GPC's splitting tensile strength.

An investigation on the GPC's durability behavior has been studied with the addition of the various $\mathrm{nS}$ dosages (0-3 percent). They noticed that with the increment of $\mathrm{nS}$ dosages, the splitting tensile strength of the GPC was increased. For instance, tensile strength at the age of 28 days was increased by $18 \%, 30 \%$, and $33 \%$ at 1,2 , and $3 \%$ dosage of $\mathrm{nS}$ content, respectively, compared to the control mixture [30]. Nuaklong et al. [26] investigated the influence of $\mathrm{nS}$ inclusion on the characteristics of a recycled aggregate fly ash-based geopolymer concrete composite. They found that the splitting tensile strength of the GPC without $\mathrm{nS}$ was $2.7 \mathrm{MPa}$, and the most excellent tensile strength value was achieved at $1 \%$ of $\mathrm{nS}$ content that is $3.0 \mathrm{MPa}$; this value was decreased slightly with adding extra content of $\mathrm{nS}$ [26]. The improvement of the splitting tensile strength at an optimum range of $\mathrm{nS}$ and decline in the tensile strength beyond that optimum dosage will argue the same as discussed in the compression strength section. Other studies with different dosages of $\mathrm{nS}$ do agree with these findings [27, 20].

A study was carried out to show the impact of $\mathrm{nS}$ and nano metakaolin on the properties of GPC [31]. They used 0, 2, 4, 6, and $8 \%$ of these $\mathrm{nS}$, and they observed that with the addition of $\mathrm{nS}$ splitting, tensile strength was improved up to an optimum dosage of the nS. At $4 \% \mathrm{nS}$ content, the maximum splitting tensile strength was observed, about $21 \%$ higher than the control mixture. While, in the event of nano metakaolin, $6 \%$ was recorded as an optimum content to give the highest splitting tensile strength $(3.9 \mathrm{MPa})$ in comparison to a reference GPC mixture (2.7 MPa) that did not contain any NPs dosage [31].

In contrast, fewer researchers $[18,24]$ declared that the use of $\mathrm{nS}$ slightly decreases the GPC's splitting tensile strength. For example, Nuaklong et al. [24] discovered that the tensile strength of the GPC mixture with 1,2 , and $3 \% \mathrm{nS}$ concentration is somewhat reduced compared to equivalent concrete mixtures without NPs. This result may be argued to the distribution of the $\mathrm{nS}$ and making weak zones by agglomeration among $\mathrm{nS}$ inside the concrete mixes, or the tensile failure may occur inside the weak aggregate particles instead of the interfacial transition zone between the strong binder pastes and the aggregate particles [24].

Table 2: Variation of the splitting tensile strength of GPC incorporating different dosages of $\mathrm{nS}$ at 28

days

\begin{tabular}{|c|c|c|c|c|c|}
\hline Authors & $\mathrm{nS \%}$ & $\begin{array}{l}\text { Splitting Tensile } \\
\text { Strength (MPa) }\end{array}$ & Authors & $\mathrm{nS \%}$ & $\begin{array}{l}\text { Splitting Tensile } \\
\text { Strength (MPa) }\end{array}$ \\
\hline \multirow[t]{2}{*}{ Çevik et al., 2018 [18] } & 0 & 4.75 & \multirow{2}{*}{$\begin{array}{c}\text { Adak et al., } 2016 \\
{[20]}\end{array}$} & 0 & 3.39 \\
\hline & 3 & 4.5 & & 6 & 4.33 \\
\hline \multirow{4}{*}{$\begin{array}{l}\text { Nuaklong et al., } 2020 \\
{[24]}\end{array}$} & 0 & 2.8 & \multirow{4}{*}{$\begin{array}{c}\text { Mahboubi et al., } \\
2019 \text { [30] }\end{array}$} & 0 & 3.7 \\
\hline & 1 & 2.7 & & 1 & 4.5 \\
\hline & 2 & 2.6 & & 2 & 5.3 \\
\hline & 3 & 2.6 & & 3 & 5.5 \\
\hline \multirow{4}{*}{$\begin{array}{l}\text { Nuaklong et al., } 2018 \\
{[26]}\end{array}$} & 0 & 2.7 & \multirow{6}{*}{$\begin{array}{c}\text { Rabiaa et al., } 2020 \\
{[31]}\end{array}$} & 0 & 2.7 \\
\hline & 1 & 3 & & 2 & 2.94 \\
\hline & 2 & 2.8 & & 4 & 3.4 \\
\hline & 3 & 2.6 & & 6 & 3.1 \\
\hline \multirow[t]{2}{*}{ Emad et al., 2018 [27] } & 0 & 5 & & 8 & 3 \\
\hline & 2 & 6.27 & & & \\
\hline
\end{tabular}




\subsection{Flexural Strength (FS)}

As illustrated in Fig. 6, several investigations have been undertaken to find out the role of $\mathrm{nS}$ inclusion on the flexural strength of geopolymer composites. Similar to the splitting tensile strength, the flexural strength tests of ASTM C78 [52], ASTM C293 [53], and or BS EN 12390-5 [54] are provided to investigate the indirect tensile strength behavior of the concrete composites. The maximum bending stress applied to the concrete before it failed is used to determine its flexural strength. Nano-silica added to geopolymer composites only slightly enhanced flexural strength.

The majority of studies found that adding $\mathrm{nS}$ to geopolymer composites improved their flexural strength. For instance, research work has been conducted by Rabiaa et al. [31] to show the influence of $\mathrm{nS}$ and nano metakaolin on GPC characteristics. They noticed that increasing the nano metakaolin content enhanced flexural strength up to $6 \%$ of the nano metakaolin dosage; then, flexural strength declined significantly. The flexural strength was $4.6,5,5.3,5.7$, and $5.5 \mathrm{MPa}$ at $0,2,4,6$, and $8 \%$ of nano metakaolin dosage, respectively; the highest flexural strength was measured at $6 \%$ of nano metakaolin dosage. In the same context, with the increment of $\mathrm{nS}$ dosage, flexural strength was increased up to $4 \%$ of nS; after that reduction in the flexural strength was recorded, the maximum flexural strength was about $23 \%$ greater than with the relative GPC mixture without any $\mathrm{nS}$ content [31].

In addition, Emad et al. [27] investigated the impact of $\mathrm{nS}$ on the mechanical properties of slag-based GPC. Compared to a control slag-based geopolymer concrete mixture without any $\mathrm{nS}$ dosage, the flexural strength of the slag-based GPC increased by $22 \%$ at the age of 28 days, including $2 \%$ of $\mathrm{nS}$ dosage. Furthermore, they also noticed that $\mathrm{nS}$ addition did not influence the shape of the crack patterns, and the plane of failure of the slag-based GPC specimens nearly falls at the middle of the specimens. This may be argued to the more homogeneity of the slag-based GPC [27]. Similar results of improving flexural strength of GPC can also be observed in other studies even though a different dosage of nS was used [26]. In contrast, fewer researchers $[18,24]$ have found that adding $\mathrm{nS}$ to the GPC reduces its flexural strength. For example, Nuaklong et al. [24] found that the flexural strength of GPC mixtures with 1,2 , and $3 \% \mathrm{nS}$ content was lowered compared to non-nS concrete compositions. Nano-silica dosages of 1,2 , and $3 \%$, for example, increased flexural strength by 28 percent, 32 percent, and 34 percent, at the age of 28 days, respectively. This finding can be discussed in the same way as the splitting tensile strength section was explained, and in addition, the incorporation of $\mathrm{nS}$ made the GPC more brittle due to strengthening the interfacial transition zone between the aggregates and the binder paste [24].

Table 3: Variation of the flexural strength of GPC incorporating different dosages of $\mathrm{nS}$ at 28 days

\begin{tabular}{ccc}
\hline Authors & nS\% & Flexural Strength (MPa) \\
\hline Çevik et al., 2018 [18] & 0 & 4.8 \\
\cline { 2 - 3 } & 3 & 4.5 \\
\hline Nuaklong et al., 2020 [24] & 0 & 5.3 \\
\cline { 2 - 3 } & 1 & 3.8 \\
\cline { 2 - 3 } & 2 & 3.6 \\
\cline { 2 - 3 } & 3 & 3.5 \\
\hline Nuaklong et al., 2018 [26] & 0 & 3.6 \\
\cline { 2 - 3 } & 1 & 4.3 \\
\cline { 2 - 3 } & 2 & 3.8 \\
\cline { 2 - 3 } & 3 & 3.6 \\
\hline
\end{tabular}




\begin{tabular}{lcc}
\hline Emad et al., 2018 [27] & 0 & 6.2 \\
\cline { 2 - 3 } & 2 & 7.84 \\
\hline Rabiaa et al., 2020 [31] & 0 & 4.6 \\
\cline { 2 - 3 } & 2 & 5 \\
\cline { 2 - 3 } & 4 & 6 \\
\cline { 2 - 3 } & 6 & 5.8 \\
\hline
\end{tabular}

\section{Conclusion}

The thorough literature analysis of the impact of $\mathrm{nS}$ addition on the resh and mechanical properties of GPC shows that the addition of the most commonly employed nanomaterial inclusion of $\mathrm{nS}$ to the GPC can:

a. Fill the pores and voids into the nanoscale, accelerate the chemical reactions among the ingredients of the GPC mixture, participate in the pozzolanic reactions, and the interfacial transition zones between the aggregate and binder pastes are improved.

b. Improve the workability of the GPC mixture up to an appropriate dosage of $\mathrm{nS}$ content, and then, reduction in the slump flow was recorded.

c. Improve the GPC's compressive strength up to an optimum dosage of the $\mathrm{nS}$ content.

d. Improve the GPC's splitting tensile strength up to an optimum dosage of the $\mathrm{nS}$ content.

e. Improve the flexural strength of the GPC up to an optimum dosage of the $\mathrm{nS}$ content.

f. Produce an eco-friendly and sustainable GPC.

\section{REFERENCE}

[1] Abdullah, Wrya A., Hemn Unis Ahmed, Younis M. Alshkane, Darko B. Rahman, Ashkan O. Ali, and Shko S. Abubakr. "The Possibility of Using Waste PET Plastic Strip to Enhance the Flexural Capacity of Concrete Beams." Journal of Engineering Research 9 (2021).

[2] Yildirim, G., Sahmaran, M., \& Ahmed, H. U. (2015). Influence of hydrated lime addition on the self-healing capability of high-volume fly ash incorporated cementitious composites. Journal of Materials in Civil Engineering, 27(6), 04014187.

[3] Yu, Q. L. "Application of nanomaterials in alkali-activated materials." In Nanotechnology in Eco-efficient Construction, pp. 97-121. Woodhead Publishing, 2019.

[4] Provis, John L., Angel Palomo, and Caijun Shi. "Advances in understanding alkali-activated materials." Cement and Concrete Research,vol.78,pp. 110-125, 2015.

[5] Abdel-Gawwad, H. A., and S. A. Abo-El-Enein. "A novel method to produce dry geopolymer cement powder." HBRC journal,vol. 12, no. 1,pp. 13-24, (2016).

[6] Sumesh, Mathialagan, U. Johnson Alengaram, Mohd Zamin Jumaat, Kim Hung Mo, and Mohammed Fouad Alnahhal. "Incorporation of nanomaterials in cement composite and geopolymer based paste and mortar-A review." Construction and Building Materials,vol. 148,pp. 62-84,(2017).

[7] Weil, M., K. Dombrowski, and A. Buchwald. "Life-cycle analysis of geopolymers." In Geopolymers, pp. 194210. Woodhead Publishing, 2009.

[8] Mohammed, Azad A., Hemn Unis Ahmed, and Amir Mosavi. "Survey of Mechanical Properties of Geopolymer Concrete: A Comprehensive Review and Data Analysis." Materials 14, no. 16 (2021): 4690.

[9] Ahmed, Hemn Unis, Ahmed Salih Mohammed, Azad A. Mohammed, and Rabar H. Faraj. "Systematic multiscale models to predict the compressive strength of fly ash-based geopolymer concrete at various mixture proportions and curing regimes." Plos one 16, no. 6 (2021): e0253006.

[10] Omer, Sharmarke Abdi, Ramazan Demirboga, and Waleed H. Khushefati. "Relationship between compressive strength and UPV of GGBFS based geopolymer mortars exposed to elevated temperatures." Construction and Building Materials,vol. 94,pp. 189-195, (2015).

[11] Duxson, Peter, Ana Fernández-Jiménez, John L. Provis, Grant C. Lukey, Angel Palomo, and Jannie SJ van Deventer. "Geopolymer technology: the current state of the art." Journal of materials science,vol. 42, no. 9,pp. 2917-2933 (2007).

[12] Ravitheja, A., and NLN Kiran Kumar. "Effect of N-Sand GGBS on the Strength Properties of Fly Ash-Based Geopolymers." In Sustainable Construction and Building Materials, pp. 449-458. Springer, Singapore, 2019.

[13] Lazaro, A., Q. L. Yu, and H. J. H. Brouwers. "Nanotechnologies for sustainable construction." In Sustainability of Construction Materials, pp. 55-78. Woodhead Publishing, 2016. 
[14] Assaedi, H., F. U. A. Shaikh, and It Meng Low. "Influence of mixing methods of nano silica on the microstructural and mechanical properties of flax fabric reinforced geopolymer composites." Construction and Building Materials,vol. 123,pp.541-552 (2016).

[15] Faraj, Rabar H., Azad A. Mohammed, Ahmed Mohammed, Khalid M. Omer, and Hemn Unis Ahmed. "Systematic multiscale models to predict the compressive strength of self-compacting concretes modified with nanosilica at different curing ages." Engineering with Computers (2021): 1-24.

[16] Roco, Michael C., R. Stanley Williams, and Paul Alivisatos, eds. Nanotechnology research directions: IWGN workshop report: vision for nanotechnology in the next decade. Springer Science \& Business Media, 2000.

[17] Falikman, Vyacheslav R., and Boris V. Gusev. "Nanotechologies in new structural concretes: Practice and outlook." In Concrete-Innovation and Design: fib Symposium Proceedings, pp. 232-234. 2015

[18] Çevik, Abdulkadir, Radhwan Alzeebaree, Ghassan Humur, Anıl Niş, and Mehmet Eren Gülşan. "Effect of NSon the chemical durability and mechanical performance of fly ash based GPC." Ceramics International,vol. 44, no. 11,pp. 12253-12264 (2018).

[19] Patel, Yagnesh, Indrajit N. Patel, and Mrs Jagruti Shah. "Experimental investigation on compressive strength and durability properties ofGPC incorporating with nano silica." Journal Impact Factor,vol. 6, no. 5,pp. 135-143, (2015).

[20] Adak, Dibyendu, Manas Sarkar, and Saroj Mandal. "Structural performance of N-Smodified fly-ash based GPC." Construction and Building Materials,vol. 135,pp. 430-439, (2016).

[21] Mustakim, Syed Mohammed, Shaswat Kumar Das, Jyotirmoy Mishra, Asif Aftab, Thamer Salman Alomayri, Hasan Suliman Assaedi, and Cyriaque Rodrigue Kaze. "Improvement in fresh, mechanical and microstructural properties of fly ash-blast furnace slag based GPC by addition of nano and micro silica." Silicon,pp. 1-14 ,(2020).

[22] Khater, Hisham Mustafa Mohamed. "Physicomechanical properties of N-Seffect on geopolymer composites." Journal of Building Materials and Structures,vol.3, no.1 ,pp.1-14,(2016).

[23] Behfarnia, K., and M. Rostami. "Effects of micro and nanoparticles of $\mathrm{SiO} 2$ on the permeability of alkali activated slag concrete." Construction and building materials,vol. 131,pp. 205-213, (2017).

[24] Nuaklong, Peem, Pitcha Jongvivatsakul, Thanyawat Pothisiri, Vanchai Sata, and Prinya Chindaprasirt. "Influence of rice husk ash on mechanical properties and fire resistance of recycled aggregate high-calcium fly ash GPC." Journal of Cleaner Production,vol. 252,pp. 119797, (2020).

[25] Ibrahim, Mohammed, Megat Azmi Megat Johari, Mohammed Maslehuddin, and Muhammad Kalimur Rahman. "Influence of nano-SiO2 on the strength and microstructure of natural pozzolan based alkali activated concrete." Construction and Building Materials,vol. 173,pp. 573-585, (2018).

[26] Nuaklong, Peem, Vanchai Sata, Ampol Wongsa, Korb Srinavin, and Prinya Chindaprasirt. "Recycled aggregate high calcium fly ash GPC with inclusion of OPC and nano-SiO2." Construction and Building Materials,vol. 174,pp. 244-252, (2018).

[27] Emad, Hala, Waleed Soufi, Ahmed Elmannaey, Magdy Abd-El-Aziz, and Hany EL-Ghazaly. "Effect of N-Son the Mechanical Properties of Slag GPC."2018.

[28] Guo, Xiaolu, Wenpei Hu, and Huisheng Shi. "Microstructure and self-solidification/stabilization (S/S) of heavy metals of nano-modified CFA-MSWIFA composite geopolymers." Construction and building materials,vol. 56,pp. 81-86, (2014).

[29] Chinthakunta, Raghavender, Durga Prasad Ravella, M. Sri Rama Chand, and M. Janardhan Yadav. "Performance evaluation of self-compacting concrete containing fly ash, silica fume and nano titanium oxide." Materials Today: Proceedings, vol. 43,pp. 2348-2354,(2021).

[30] Mahboubi, Behnam, Zuhua Guo, and Hao Wu. "Evaluation of durability behavior of GPC containing N-Sand Nano-clay additives in acidic media." Journal of civil Engineering and Materials Application,vol. 3, no. 3,pp. 163-171 (2019).

[31] Rabiaa, E., R. A. S. Mohamed, W. H. Sofi, and Taher A. Tawfik. "Developing GPC Properties by Using Nanomaterials and Steel Fibers." Advances in Materials Science and Engineering,vol. 2020, (2020).

[32] Abbasi, Saloumeh Mesgari, Hamidreza Ahmadi, Gholamreza Khalaj, and Bahar Ghasemi. "Microstructure and mechanical properties of a metakaolinite-based geopolymer nanocomposite reinforced with carbon nanotubes." Ceramics International, vol. 42, no. 14,pp. 15171-15176, (2016).

[33] Zhang, Min-Hong, Jahidul Islam, and Sulapha Peethamparan. "Use of N-Sto increase early strength and reduce setting time of concretes with high volumes of slag." Cement and Concrete Composites,vol. 34, no. 5,pp. 650662, (2012).

[34] Aggarwal, Paratibha, Rahul Pratap Singh, and Yogesh Aggarwal. "Use of N-Sin cement based materials-A review." Cogent Engineering,vol. 2, no.1,pp.1078018 (2015).

[35] Nazari, Ali, and Shadi Riahi. "The effects of $\mathrm{Cr} 2 \mathrm{O} 3$ nanoparticles on strength assessments and water permeability of concrete in different curing media." Materials Science and Engineering: A,vol. 528, no. 3,pp. 1173-1182 (2011).

[36] Parveen, Shazia, Abdul Hamid Wani, Mohammad Ashraf Shah, Henam Sylvia Devi, Mohd Yaqub Bhat, and Jahangir Abdullah Koka. "Preparation, characterization and antifungal activity of iron oxide nanoparticles." Microbial pathogenesis,vol. 115,pp. 287-292, (2018).

[37] Hussin, M. W., M. A. R. Bhutta, M. Azreen, P. J. Ramadhansyah, and J. Mirza. "Performance of blended ash GPC at elevated temperatures." Materials and Structures,vol. 48, no. 3,pp. 709-720, (2015). 
[38] Abhilash, P. P., Dheeresh Kumar Nayak, Bhaskar Sangoju, Rajesh Kumar, and Veerendra Kumar. "Effect of nano-silica in concrete; a review." Construction and Building Materials 278 (2021): 122347.

[39] Bahij, Sifatullah, Safiullah Omary, Francoise Feugeas, and Amanullah Faqiri. "Fresh and hardened properties of concrete containing different forms of plastic waste-A review." Waste Management,vol. 113,pp.157-175 ,(2020).

[40] Alshkane, Younis Mustafa, Serwan Khorsheed Rafiq, and Hemn Unis Boiny. "Correlation between Destructive and Non-Destructive Tests on the Mechanical Properties of Different Cement Mortar Mixtures incorporating Polyethylene Terephthalate Fibers." Sulaimania Journal for Engineering Sciences 4, no. 5 (2017).

[41] Standard Test Method for Slump of Hydraulic-Cement Concrete, ASTM C143-15.

[42] ASTM C1611/C1611M-18."Standard Test Method for Slump Flow of Self-Consolidating Concrete". American Society for Testing and Materials,2018.

[43] The European Standard BS EN 12350-3, testing of fresh concrete: part-3: vebe test, 2009.

[44] The European Standard BS EN 12350-4, Testing of fresh concrete: part-4: degree of compactibility, 2009.

[45] The European Standard BS EN 12350-5: Testing of fresh concrete: part-5: flow table test,2009.

[46] Ahmed, Hemn Unis, Rabar H. Faraj, Nahla Hilal, Azad A. Mohammed, and Aryan Far H. Sherwani. "Use of recycled fibers in concrete composites: A systematic comprehensive review." Composites Part B Engineering (2021): 108769.

[47] Standard Test Method for Compressive Strength of Cylindrical Concrete Specimens, ASTM C39-17.

[48] Standard, British. "Testing hardened concrete." Compressive Strength of Test Specimens, BS EN,pp. 12390-3 ,(2009).

[49] Standard Test Method for Splitting Tensile Strength of Cylindrical Concrete Specimens, ASTM C496- 11.

[50] The European Standard BS EN12390-6, testing on hardned concrete: part-6: tensile splitting strength of test specimens, 2009.

[51] Boiny, Hemn U., Younis M. Alshkane, and Serwan Kh Rafiq. "Mechanical properties of cement mortar by using polyethylene terephthalate fibers." In 5th National and 1st International Conference on Modern Materials and Structures in Civil Engineering, Iran (Islamic Republic of Iran). 2016.

[52] Standard Test Method for Flexural Strength of Concrete (Using Simple Beam with Third-Point Loading), ASTM C78-16.

[53] Standard Test Method for Flexural Strength of Concrete (Using Simple Beam with Center-Point Loading), ASTM C293-16

[54] The European Standard BS EN12390-5, testing on hardned concrete: part-5: flexural strength of test specimens, 2009.

[55] Naskar, Sudipta, and Arun Kumar Chakraborty. "Effect of nano materials in geopolymer concrete." Perspectives in science 8 (2016): 273-275. 